ГАМАН-ГОЛУТВИНА Оксана Викторовна - доктор политических наук, профессор, членкорреспондент РАН; заведующий кафедрой сравнительной политологии Московского государственного института международных отношений (университет) МИД РФ (119454, Россия, г. Москва, nр-кm Вернадского, 76, корп.B; ogaman@mail.ru)

СМОРГУНОВ Леонид Владимирович - доктор философских наук, профессор; заведующий кафедрой политического управления Санкт-Петербургского государственного университета (191124, Россия, г. Санкт-Петербург, ул. Смольного, 1/3, под. 7; lvsmorgunov@gmail.com)

ТИМОФЕЕВА Лидия Николаевна - доктор политических наук; профессор кафедры политологии и политического управления, научный руководитель школы политических исследований Института общественных наук Российской академии народного хозяйства и государственной службы при Президенте РФ (119606, Россия, г. Москва, np-кm Вернадского, 84; timofeeva-lidiya@inbox.ru)

\title{
КОНСТИТУЦИОННЫЕ ИЗМЕНЕНИЯ, ВЛАСТЬ И ПОЛИТИКА
}

\author{
Итоги Всероссийской научной конференции РАПН с международным \\ участием «Политическое представительство и публичная власть: \\ трансформационные вызовы и перспективы», 27-28 ноября 2020, \\ МПГУ, Москва
}

Аннотация. 27-28 ноября 2020 г. в Москве прошла ежегодная всероссийская научная конференция старейшей в стране Российской ассоциации политической науки (РАПН), которой как раз исполнилось 65 лет. Конференция была посвящена теме «Политическое представительство и публичная власть: трансформационные вызовы и перспективы». Эта тематика связана с двумя политическим событиями: во-первых, с изменениями в Основном законе страны, во-вторых, с очередными выборами в Государственную думу РФ в 2021 г.

Ключевые слова: политическое представительство, публичная власть, конституционные изменения, выборы

B сероссийская научная конференция самой авторитетной в стране Российской ассоциации политической науки (РАПН), которой как раз исполнилось 65 лет, традиционно прошла в Москве 27-28 ноября 2020 г. Она была посвящена теме «Политическое представительство и публичная власть: трансформационные вызовы и перспективы». Эта тематика связана с двумя политическим событиями. Во-первых, в обновленную Конституцию РФ, которая была одобрена общероссийским голосованием 1 июля 2020 г., наряду с другими важными поправками, вошло понятие «публичная власть». Во-вторых, в 2021 г. пройдут выборы депутатов Государственной думы Федерального собрания РФ. При довольно низком доверии граждан к политическому представительству и деятельности соответствующих институтов власти эта тема является весьма актуальной и политически острой.

А при учете цифровизации, которая сегодня трансформирует политическую коммуникацию и мобилизационные механизмы участия, серьезно проблематизируя политическое представительство, умножая многообразие сюжетных линий, эта тема не могла пройти без серьезного обсуждения. В этом отношении «трансформационные вызовы и перспективы» как задача конференции вполне охватывают перспективную тематику научных исследований.

Конференция была приурочена к началу юбилейного года - года 65-летия РАПН, началом организации которой явилось участие отечественных политических исследователей в III Всемирном конгрессе Международной ассоциации 
политической науки в 1955 г. в Стокгольме (Швеция). Российская ассоциация политической науки является крупнейшей профессиональной организацией в области политических исследований и политического образования в стране, целями которой выступают содействие развитию политической науки и реализации результатов научно-исследовательской деятельности в современном обществе, в деятельности органов государственной власти, органов местного самоуправления, политических партий и общественных объединений, а также граждан; содействие повышению уровня исследований и преподавания в области политической науки; организация и проведение политологических исследований; участие в экспертизе и аккредитации образовательных учреждений, стандартов и программ в порядке, предусмотренном федеральными законами; консолидация российского профессионального политологического сообщества; развитие международного сотрудничества в области политической науки. Реализуя эти цели и задачи развития политической науки в стране, РАПН в 2020 г. провела крупномасштабное мероприятие - всероссийскую научную конференцию с международным участием РАПН'2020.

В конференции приняли участие более 500 человек из 50 регионов России, а также из 12 государств ближнего и дальнего зарубежья. На ней были представлены все основные центры развития политических наук, включая университеты и академические институты Москвы, Санкт-Петербурга, Перми, Томска, Екатеринбурга, Краснодара, Саратова, Симферополя, Калининграда, Ростова-на-Дону, Воронежа, Ярославля и др. городов. В рамках конференции состоялось более 70 заседаний (секций, круглых столов, сессий исследовательских комитетов, специальных заседаний, презентаций). Пленарное заседание состоялось в смешанном (очно-дистанционном) формате, секционные заседания - преимущественно в дистанционном формате на цифровой платформе BigBlueButton $(B B B)$. Пленарное заседание транслировалось на канале YouTube. Техническую и организационную поддержку оказывал Московский педагогический государственный университет (МПГУ). Часть форматов была осушествлена при поддержке МГИМО. Информационную поддержку конференции оказывали журналы «Полис. Политические исследования», «Власть», «Политическая наука», «Политическая экспертиза. Политэкс», «Конфликтология», «Сравнительная политика».

В адрес конференции поступили приветствия первого заместителя руководителя Администрации Президента России C.B. Kириенко; председателя Комитета Государственной думы по образованию и науке ФС России, декана факультета государственного управления МГУ им. М.В. Ломоносова, сопредседателя президиума РАПН профессора $\boldsymbol{B . A}$. Никонова; ректора МГИМО, сопредседателя президиума РАПН академика РАН $\boldsymbol{A}$.B.Tоркунова; ректора МПГУ члена-корреспондента РАО, профессора $\boldsymbol{A . B . ~ Л у б к о в а ; ~ с о п р е д с е д а т е л я ~ Р о с с и и ̆ с к о г о ~ о б щ е - ~}$ ства политологов, декана факультета политологии МГУ им. М.В. Ломоносова профессора А.Ю. Шутова и представителей других институциональных структур страны.

Пленарное заседание открыла президент Российской ассоциации политической науки, председатель ФУМО «Политические науки и регионоведение», член Общественной палаты России, Общественной палаты Москвы и Общественного совета при Минобрнауки, заведующая кафедрой сравнительной политики МГИМО МИД РФ, чЛ.-Корр. РАН О.В. Гаман-Голутвина. В своем вступительном слове она обозначила требующие обсуждения актуальные тематические направления современной политической науки, среди которых - источники, факторы и риски глобальной турбулентности; проблемы сопряжения интересов и институтов национального государства и векторов процес- 
сов глобализации; необходимость и возможности инкорпорации повестки развития с ненулевой суммой в глобальную повестку; «горячие точки» мировой политики, включая конфликты в Сирии и Карабахе; результаты и последствия выборов в США, Беларуси, Молдове и других государствах; отношения России с основными институциональными акторами мировой политики; преимущества, риски, субъекты и тенденции развития процессов цифровизации; актуальная внутриполитическая повестка России, включая предстоящие выборы депутатов Государственной думы; процессы в молодежной среде России и другие темы.

С докладом «Актуальность вектора публичной политики в современной России и основные ресурсы ее осуществления» выступила доктор философских наук, профессор МПГУ, ведущий научный сотрудник Института философии РАН A.Г. Глинчикова. Она рассмотрела вопросы соотношения задач органов государственной власти и роли общественных ассоциаций, влияние общественного мнения на государственную политику, особо выделив различные ресурсы общественного развития: критические, ценностные и культурные, образовательные, организационно-управленческие, информационные и др.

В своем докладе «Управление сетевыми сообществами в онлайн-пространстве публичной политики: ресурсы и технологии» доктор политических наук, профессор, заведующая кафедрой Кубанского государственного университета И.В. Мирошниченко уделила внимание трем типам сетевых сообществ, формирующихся и функционирующих в политическом пространстве публичной политики: институционализированным, транзитным, активно действующим. Результаты эмпирического исследования, основанного на сборе, анализе и визуализации открытых сетевых данных, показали, что наиболее дифференцированными по своим субъектным характеристикам являются активно-деятельностные сообщества. В докладе выделялись основные технологии активизации сетевых сообществ в публичной политике.

Доктор политических наук, доцент, заведующий кафедрой Ярославского государственного университета $\boldsymbol{A}$. B. Соколов представил доклад «Цифровизация гражданской активности в современной России: особенности, тенденции и основные тематики». На его взгляд, социальные сети представляют собой не только удобную площадку для коммуникации и распространения информации, но и информативный источник данных для политического анализа. Это в первую очередь связано с тем, что современная общественно-политическая активность переходит в онлайн-форматы. Появляются новые способы политической коммуникации, манипулирования, агитации, мобилизации. Он выделил такие формы выражения активности, как посты, лайки, репосты, комментарии, публикации с тематическими хэштегами и т.д., и показал возможности их использования для постановки вопросов политической повестки.

В докладе доктора политических наук, профессора, заведующего кафедрой МГУ им. М.В. Ломоносова В.И. Якунина на тему: «Политическое представительство, политическая идентичность и вызовы современной государственной политики» обращается внимание на современный разнонаправленный кризис общественного развития с акцентом на неготовности государства и государственного управления к адекватному ответу на него. Выступая с докладом на тему: «Власть в России: политическая, публичная, представительная?» кандидат исторических наук, руководитель отдела сравнительных политических исследований Института социологии Федерального научно-исследовательского социологического центра $\boldsymbol{C}$. B. Патрушев поставил ряд вопросов, относящихся к незавершенности институциональных порядков и институциональной неопределенности публичного пространства России. По его мнению, 
новые подходы необходимы для конституирования политического пространства, поля политики и институционализации гражданской активности.

«Город как политическая реальность новой эпохи» - тема выступления доктора политических наук, профессора, заведующего кафедрой Томского государственного университета $\boldsymbol{A . И . ~ Щ е р б и н и н а . ~ О н ~ д а в н о ~ и з у ч а е т ~ г о р о д ~ к а к ~ о д и н ~}$ из ведущих политических акторов в ансамбле политики XXI столетия. В его докладе обращается внимание на то, что меняющаяся эпоха обострила теоретический интерес к онтологии современного города и политическую прагматику, к его потенциалу в условиях глобальной конкуренции, к внутренним ресурсам устойчивого развития, а также к возможным рискам и угрозам. Фактически мы находимся на пороге рождения такого исследовательского направления, как политическая урбанистика. В докладе «Технологии политической онлайн-мобилизации российской молодежи» доктор политических наук, профессор, заведующая кафедрой СПбГУ O.B. Попова рассматривала политическую онлайн-мобилизацию как интернет-деятельность политических акторов, направленную на форсированное достижение поставленных политических целей посредством активизации политического участия масс. На основании эмпирических исследований подчеркивалось, что молодежь своими действиями демонстрирует остро неприязненное отношение к несовершенству социальных и политических отношений, завышенные притязания к окружающим, осознание собственной субъектности в системе социальнополитических отношений при невозможности реализовать этот потенциал в полной мере.

Развитие этой актуальной проблемтики продемонстрировал доклад доктора политических наук, профессора, заведующей кафедрой Алтайского государственного университета Я.Ю. Шашковой на тему: «Политические ценности и установки учащейся молодежи Сибири и Дальнего Востока». В нем нашли освещение проблемы формирования различных ценностей молодежи в онлайн-пространстве. Было подчеркнуто, что различные возрастные группы в силу своей цифровой компетентности и доминирующих политических установок по-разному реагируют на эти процессы. Политический процесс воспринимается современной молодежью контекстно и не дифференцированно по уровням. Она очень рано вырабатывает навыки быстрого сканирования информации и ее критической оценки на основе собственного мнения. Интернет сдвигает возраст начала политической активности подрастающего поколения в сторону «омоложения».

В рамках пленарного заседания состоялась презентация нового электронного ресурса РАПН «Библиотека конфликтолога. Онлайн-библиотека документов, книг, статей, фото-, видеоматериалов по конфликтам в ареале интересов России». Этот проект представил его руководитель - доктор политических наук профессор МГИМО МИД РФ А.И. Никитин.

Программа конференции включала в себя обсуждение широкого спектра тем. Основными проблемными векторами обсуждения были публичная власть и структурные и функциональные вызовы в эпоху кризисов; теория власти и господства; кризис политической репрезентации и его преодоление; парламентаризм в современном мире; конституция и публичная власть; политические партии и политическое представительство; выборы и публичная власть; выборы депутатов Государственной думы 2021 г.: вызовы и прогнозы; разделение властей; право, политика, технология; федерализм и публичная власть; публичная власть и прямая демократия; гражданское участие и публичная власть.

Общим итогом состоявшихся заседаний по основной теме конференции 
стало понимание сложных и масштабных политических процессов, которыми характеризуется современное развитие России и мира. Во-первых, публичная власть, реализуемая народом посредством органов государственной и муниципальной власти, в современных условиях трансформируется в направлении более широкого и сложного взаимодействия ее прямых представительных, исполнительных и судебных форм. В этом смысле конституционные изменения не просто систематизируют понятие власти в стране, а задают институциональный вектор ее развития. Во-вторых, обсуждение проблем конституционных изменений показало, что как в России, так и в ряде других стран конституционный процесс подвержен естественному развитию как под воздействием политических трансформаций, так и вследствие своей собственной логики конституционной политики. В-третьих, политические проблемы организации публичной власти являются чувствительным нервом политической жизни общества, вовлекая в их решение не только специалистов в области права, политиков, деятелей государства, политические партии, СМИ, ученых, но и граждан страны. Не случайна и форма легитимации конституционных изменений в России посредством всеобщего голосования. В-четвертых, ясно, что конституционный процесс будет влиять и на предстоящие парламентские выборы в России 2021 г. Политические партии, кандидаты в депутаты Государственной думы, избиратели, все институты, вовлеченные в избирательный механизм, должны будут откликаться на принятые изменения и строить свою стратегию, не только руководствуясь видением перспектив развития страны, но и учитывая политико-правовые рамки конституции. В-пятых, сам характер «живой конституции» свидетельствует, что политическая система страны, разделение властей, федерализм, гражданское участие, права и свободы, суверенитет страны и международное сотрудничество и влияние - все это подвержено естественному процессу политической жизнедеятельности, отрицающей стагнацию и догматизм, требующей плюрализма и консолидации, единства и различия, рассуждения и общественного утверждения.

По различной проблематике состоялись заседания 22 исследовательских комитетов РАПН. Проблематика специальных заседаний и круглых столов включала в себя вопросы политической философии; институтов и практик взаимодействия власти, экспертного сообщества и общественных организаций в российских регионах; феномена города как политической идеи (пространства смыслов в нем, репрезентации, коммуникации); конфликтологического аудита в российских регионах, включающего содержание, эффекты и проблемы их развития; политических ценностей и установок современной российской молодежи; политического $P R$ и его коммуникационных стратегий, а также особенностей политического языка в эпоху мировой пандемии; местного самоуправления и государственной власти в современной России; образа будущего России как проблемы политической науки и политической практики; политической онтологии цифровизации публичного управления; трансформации мира и политики после COVID-19; мобилизации и демобилизации в политическом протесте; направлений, форм и механизмов взаимодействия молодежи и публичной власти; прогнозирования в международных отношениях в эпоху турбулентности; человеческого потенциала/капитала политических элит в системе отношений «центр - регионы».

Отметим, что многие заседания, доклады и выступления являлись реализацией научно-исследовательских проектов, которые были поддержаны различными институтами и фондами. Особо следует отметить многообразие грантовых научных проектов, получивших финансирование со стороны президента РФ, Российского фонда фундаментальных исследований (РФФИ), Российского 
научного фонда (РНФ), совместных проектов РФФИ и Экспертного института социальных исследований (ЭИСИ) и др.

Состоялось специальное заседание президиума Академии политической науки на тему: «Ленинское теоретическое наследие и современная политическая наука (к 150-летию со дня рождения В.И. Ленина)». Прошло заседание Совета молодых политологов, а также состоялась презентация журнала «Политическая наука».

В рамках конференции было организовано традиционное ежегодное собрание РАПН с участием членов правления, научного совета РАПН и руководителей региональных отделений ассоциации. На собрании были подведены итоги прошедшего года (отчеты представили председатель правления, вице-президент РАПН, научный руководитель Школы политических исследований ИОН РАНХиГС при Президенте РФ профессор Л.H. Тимофеева и председатель научного совета, вице-президент РАПН, заведующий кафедрой СПбГУ профессор Л.В. Сморгунов). Были обнародованы итоги ежегодного конкурса РАПН на лучшие монографии и учебники (дипломы различной степени получили ученые Воронежа, Москвы, Перми, Санкт-Петербурга, Томска).

Подведение итогов конференции показало, что в достаточно сжатые сроки ее регламента исследователям, преподавателям, экспертам, аспирантам и студентам удалось продуктивно обменяться идеями и плодотворно поработать на виртуальных площадках конференции.

Важно, что была достигнута цель конференции - способствовать разработке в российской политической науке проблематики представительства и публичной власти в условиях их трансформации, а также внедрению новых подходов к современной публичной политике и управлению путем сочетания институционального, сетевого, коммуникативного, конфликтологического и идейционистского подходов; укрепить единство теории и практики в преподавании общественных дисциплин в вузах. Она продемонстрировала, что российские политологи стали чаще проводить исследования по важнейшим направлениям и проблемам современной политики и науки. Этому способствует финансовая поддержка многих проектов российскими научными фондами. И состовшаяся конференция прошла при финансовой поддержке РФФИ, грант № 20-011-22039 \20. Поддержку конференции оказывали Московский педагогический государственный университет, МГИМО МИД России, Академия политической науки, научные журналы «Политические исследования. Полис», «Власть», «Политическая наука», «Сравнительная политика», «Конфликтология», «Политическая экспертиза. Политэкс».

По ее итогам издан сборник материалов конференции ${ }^{1}$. Все участники выразили надежду на проведение следующего крупного мероприятия РАПН в 2021 г. - IX Всероссийского конгресса политологов - в традиционном очном формате, поскольку «живое» общение и энергетика непосредственных творческих контактов, при всем кажущемся удобстве и эргономии, не могут быть заменены даже «высокими технологиями».

1 Политическое представительство и публичная власть: трансформационные вызовы u nерспективы. Материалы Ежегодной всероссийской научной конференции с международным участием РАПН'2020. Москва, МПГУ, 27-28 ноября 2020 г. (под ред. О.В. Гаман-Голутвиной, Л.В. Сморгунова, Л.Н. Тимофеевой). М.: Изд-во МПГУ. 2020. 620 с. 
GAMAN-GOlUtVINA Oksana Viktorovna, Dr.Sci. (Pol.Sci.), Professor, Corresponding Member of the Russian Academy of Sciences; Head of the Chair of Comparative Politics, Moscow State Institute of International Relations, University of the Ministry for Foreign Affairs of Russia (76 Vernadskogo Ave, Moscow, Russia, 119454; ogaman@mail.ru) SMORGUNOV Leonid Vladimirovich, Dr.Sci. (Philos.), Professor; Head of the Chair of Political Management, St. Petersburg State University (7th entr, 1/3 Smol'nogo St, St. Petersburg, Russia, 191124; lvsmorgunov@gmail.com) TIMOFEEVA Lidiya Nikolaevna, Dr.Sci. (Pol.Sci.), Professor of the Chair of Political Science and Political Administration, Scientific Director of the School of Political Studies, Institute of Social Sciences, Russian Presidential Academy of National Economy and Public Administration (RANEPA) (84 Vernadskogo Ave, Moscow, Russia, 119606; timofeeva-lidiya@inbox. ru)

\title{
CONSTITUTIONAL CHANGES, POWER AND POLITICS
}

Results of the All-Russian Scientific Conference of RAPN with International Participation «Political Representation and Public Power: Transformational Challenges and Prospects», November 27-28, 2020, IPSU, Moscow

\begin{abstract}
On November 27-28, 2020, Moscow hosted the annual all-Russian scientific conference of the country's oldest Russian Association of Political Science (RAPN), which just turned 65 years old. It was dedicated to the topic «Political Representation and Public Power: Transformational Challenges and Prospects", linked to two political events. First, this is changes to the constitution of the country by the all-Russian vote on July 1, 2020. The updated Constitution of the Russian Federation, among other amendments, includes the concept of public power, which reflects the significant changes that have occurred in the socio-political practice of interaction between the state and society. Secondly, this is the next elections to the State Duma of the Russian Federation in 2021. The actualization of the relevant issues affects not only the political process as a whole (political parties, nomination of candidates, discussions and agenda, voting, etc.), but also the impact on it of the expanded functions of public authorities in the updated Constitution.
\end{abstract}

Keywords: political representation, public power, constitutional changes, elections 